\title{
Tattoos in the Medical Practice
}

\author{
Nelson Eduardo Alvarez Licona ${ }^{1 *}$, María Luz Sevilla González ${ }^{1}$, Ricardo Alvarez Sevilla $^{2}$ \\ ${ }^{1}$ Instituto Politécnico Nacional, CD México \\ ${ }^{2}$ Escuela Nacional de Antropologia e Historia, CD México \\ Email: ^nalvarez@ipn.mx
}

How to cite this paper: Álvarez Licona, N. E., Sevilla González, M. L., \& Alvarez Sevilla, R. (2019). Tattoos in the Medical Practice. Advances in Anthropology, 9, 80-94. https://doi.org/10.4236/aa.2019.91006

Received: November 13, 2018

Accepted: February 16, 2019

Published: February 19, 2019

Copyright $\odot 2019$ by author(s) and Scientific Research Publishing Inc. This work is licensed under the Creative Commons Attribution International License (CC BY 4.0).

http://creativecommons.org/licenses/by/4.0/

Open Access

\begin{abstract}
Since remote times, there have been records that have stated the practice of tattooing in many cultures. The techniques and tools used are related to the senses as well as the functions of social practices, hence the development of diseases is related to therapeutic practices. The purpose of this research is to identify the construct as the foundation of decision making which is related to the reality from the perspective of someone. Tattooing practice possesses a magical sense due to the symbols and the understanding of the body as a map whose functioning and representations have led humans to recur tattooing as a therapeutic resource. Moreover, tattooing practice is about an effect of decision making. This paper registers different techniques from the Western as well as some traditional cultures that use tattooing as a therapeutic resource.
\end{abstract}

\section{Keywords \\ Tattoo, Culture, Identity, Disease, Magical Thinking}

\section{Introduction}

When people talk about tattoos, the first question that comes to someone's mind is why people tattoo. The most common answer should be wide enough that may lead to many phenomena that propose a generative mechanism for tattooing practice. The reasons most argued by the people interviewed are: 1) with an aesthetic sense, it is very common in Western culture; 2 ) to keep in mind the beloved person, for this, faces or names are tattooed; 3) to remember significant events, for which dates are tattooed; 4) as a symbol of group identity, to be shared the same script by different people, for example the winged skulls that is common among groups of motorcyclists; 5) with a playful sense, for which drawings are used as caricatures or legends; 6 ) as a manifestation of belonging to certain lineages, such as tattoos on the chin that are performed by Berber women 
in Morocco; 7) manifestation of the changes that happen to the subjects, such as the use of tattoos to manifest changes in the body; 8) as a protective object, religious images or other objects are tattooed; 9) as a healing technique, related to magical-religious thought, such as lines, crosses and circles which are carried out by Berber women in Morocco to combat goitre or joint pains; 10) as a protective magic mechanism against the "Evil Eye", which is carried out by the Berber women in Morocco, being the lines, crosses and circles. This explanatory mechanism is based on the way reality is interpreted; this is the reason why it is relevant to consider how the subjects build their reality and the interaction with the phenomena that makes possible this practice. Identity is a real state and a construct of what people perceive. A category of the state is used to show quality, condition, circumstance, character, nature, temperament; whereas construct category is used to show construction, creation, disposal, and regulation.

Reality state is understood, in our own existence, where we are being and where we are existing. In the sense of our existence, there is the condition that people are an incarnation of the society given the contexts. Furthermore, people are their own existence in which a particular and optical reality is created. Once this fact is understood, identity is a constant experience; an occurred event; and an answer to a specific situation. Identity is a constant process of change; its reference is the history that allows us to understand who we really are since, based on the reference, our actions make sense with the continuity of the idea we have. This same reference is the foundation used to interpret reality because at all times reality is being built because it is an interpretation of what is done and what is captured by the senses. Once reality is perceived, people make a picture of it, and this picture is the sense of what is captured, thus we may be in known realities; it is important to mention that the only unknown thing is what we can't create a picture of it according to our perception. It depends on the interpreted criteria people possess based on the learning process they acquired and related to the own structures of the society they used for their contexts. Those contexts are related to the living conditions shared by the members. Our behavior and image show the underlain structures and are found within the social groups due to the social conditions of existence. Interpretations and behaviors are caused by these structures creating uniformity to understand the reality shown through the identity. "Society, among its institutions, values, concepts, and language is sociologically prior to its particular members who become men through the education or adaptation in a determined society" (Dumont, 1987: p. 15). For instance, during the formation process of the western culture, the formation of an individual consciousness has been the base of a social organization. The structures used in western law subordinate the function of the individual. It is completely different in other cultures where being individual does not exist like in India where being social is everything, and the person depends on the society by looking for its logic within the subordinated hierarchical structures. Based on the fact that holistic societies understand each other hierarchically, it is difficult that 
western cultures can understand them because, in western cultures, people understand and are taught that being individual is everything, whereas in the other cultures society is the reference used for the social construction of reality as the elements of the "us" creation.

Understanding the existence, based on an equal or hierarchical principle, leads to basic realities used to interpret the reality. Notwithstanding, either individual or holistic consciousness used to understand the reality come from a social training. So, even though there are two different societies, their particular organized ways are only a single and universal way. Regarding the traditional cultures, they do not categorize equality as a value; moreover an "individual" category could not be used to name their members; what these traditional cultures have in common with the modern ones is the social man, so it is the link for us to understand them (Dumont, 1970: p. 5-11).

Just like identity construction is based on individual reference or on a holistic consciousness, reality can also be interpreted from magic-religious explanations as well as from a scientific objectivity; these two factors are basic for the construction of reality, and for the idea we have of identity. The mythical thinking as well as the scientific knowledge is transmitted by the institutions in charge. The institutions can be schools, which transmit knowledge freely, or the media, which transmit knowledge restrictedly as the initiatory knowledge taught secretly. It does not matter how knowledge is transmitted; society itself manage the way to interpret reality based on scientific, lay, and demystified knowledge; or based on mythical, sacred, and allegoric knowledge although we do not realize that our practices are based on mythical interpretations of reality. "Scientific thinking asks questions, and mythical thinking answers them. Obviously, the explanations are not in the same channel of the question; they are two ways of using reason, and two procedures that lead to an order and intelligibly in the universe" (Balandier, 1993: p. 17).

Having these two references lead to different reasons why people tattoo. For instance, they want to outstand within a society by being acknowledged through a mark. In some cases, a permanent mark on the skin is seen as a new attribute done by a member of the society. The permanent and new mark is considered an attribute that is now part of the identity of the member. Tattoos indicate the new attributes of the member that wears them; therefore, this practice is associated with some rituals in some cultures like in New Guinea where people tattoo as their age increases; in New Guinea, women start this practice at the age of five. As they get older, the number of tattoos increases. they get their last tattoos on the breast in a V-shape when they are old enough to get married (Addon, 1922: p. 23).

Moreover, regarding the sense of being different within the society, the practice of tattooing was carried out as an act of denigration towards other men in order to make unfair distinctions among the members of the society; to create negative attributes for classifying people just like the Nazis did to prisoners of 
the concentration camps; or like in France where according to the act 1791, recidivists were marked with an R following Floreal X act (Foucault, 1995: p. 105).

Nevertheless, not only tattoos are used for these reasons mentioned above, but also they are used for a functional efficiency like the Fang in West Africa because they want to emphasize their facial features. The tattoos of this community are in all volumes on and surfaces of the human body; sometimes, tattoos emphasize their facial features discreetly or bluntly, there by strengthening their expressiveness" (Sabater, 1992: p. 228). Convenient and suitable decisions led to the effectiveness of tattooing because in some situations during the $8^{\text {th }}$ century sailors had to tattoo religious images on their backs in order to avoid being flagellated as a punishment. Nevertheless, if they did not do so, they tended to think that no one would hurt them or if they would do so, the flagellation would make them lose track (Wroblewski, 1981: p. 9-13).

Acknowledging these reasons and watching the phenomena make us realize tattoos as a polysemic possibility, as multiple ways of expression for both the people who wear them and the people who watch them. This is the reason why we believe this research should be carried out from the identity perspective, hence it is necessary to undertake this research on the basis of society. It is important to mention that the study of society makes us understand that these practices are related to the underlain structures of the social organization as well as the social living conditions. The same social organization where we can find different ways of interpreting reality which is shared by the members of the society that perform this practices. These ways of interpreting reality are perfectly established based on their meaning, type of graphic, the part of the tattooed body, and the ritual used to mark their bodies. Regarding western society, these practices are also homologous and explain the creation of habitus, i.e., even though they are not considered a mandatory nor a strategic calculus, they are indeed considered predictable like tattooing practices in prison where these practices create homologous relations due to the homogeneity diversity (Bourdieu, 1991: p. 104). The result of this is that essential biographic fact of the tattooed subjects must be taken into account. Therefore, we are going to explain this phenomenon once we have described it based on the acknowledgment of the reasons that support the practice, and based on looking for the explanations in the subject and not in the graphic itself. So, we are going to explain this cultural way of expression without categorizing tattooing arbitrarily just like it has been done until now (Lombroso, 1886; Locard, s/f; Martínez, 1899; Di Tullio, 1966; Meton, 1966; García, 1994).

\section{Methodology and Research Techniques}

The corpus of this research is made of 70 informal and semi-addressed interviews to tattooed people. Each interview lasted between 10 to 20 minutes, so there was the opportunity to get new information. These interviews were carried out based on 7 initial questions in order to gather, every time, new information 
about tattooing practices making the interviews semi-addressed. So, we had the chance of addressing topics based on the following questions: where and when did you get your tattoo?; how and with what?; why and what does it mean?; is there any relation between your tattoo and the part of your body you tattooed? The questions were asked following that order (first the technical questions), so the interviewer could approach the interviewee by sharing valuable information for both, thereby creating a reciprocal exchange. This exchange facilitated gathering ordinary information and more intimate information like why the subject got tattooed and the meaning of his/her graphic. They were asked for their consent to be able to tax the interviews and to take the photographs.

Moreover, the corpus has ethnographic material from different libraries: National Library of Mexico and the National Library of Madrid where plenty of information about ethnographic descriptions in tattooing practices was gathered.

The people were recruited at the convenience of the researcher, evaluating from the beginning the willingness of the subjects to participate, interviewing subjects tattooed from the chosen spaces, which affect the decision making regarding the practice of tattooing, to build the sample: 1) Tattoos in Western culture, interviews were held in Mexico City and in the city of Madrid; 2) Tattoos in a Total Institution (Goffman, 1992), is interviewed people tattooed in the Federal Penal Colony Islas Marías, which is a jail in Mexico; 3) Tattoos that were made as part of a traditional culture, to observe it as an everyday practice forming part of the common sense of tattooed subjects, for this interviews were conducted in Sidi-Fadma, Berber community $50 \mathrm{~km}$ from Marrakech to the region of the Great Atlas. In Madrid and Mexico City, 35 people were interviewed. In the Islas Marías Federal Penal Colony, Mexican jail, 25 interviews. In Marrakech and Sidi-Fadma, a Berber community $50 \mathrm{~km}$ from Marrakech to the region of the Grande Atlas, Morocco, 10 interviews were conducted.

This paper organizes the analysis proposal among with the tattooing practice in Islas Marías Federal Penal Colony where this workstation was set for 11 months. The gathered material gave us samples of tattooing in a "Total Institution" (Goffman, 1992) apart from the other material that led to an ethnological study in the Penal Colony. Interviews were carried out in Madrid and in Mexico to have samples from Western cultures societies. Moreover, Berber Muslim women were interviewed and they gave us information about the tattooing practice in their traditional society (the population is $50 \mathrm{~km}$ away from Marrakech, in the Atlas Mountains of Morocco).

\section{Mythical Thinking and Therapeutic Tattoos}

“The sociologist can't spend time verifying scientifically the subject's beliefs. The efficacy of the ideas, beliefs, consciousnesses does not depend on whether they are true or false; rather their capacity to determine the behavior and their social evidence range, in other words, efficacy depends on the power, and the capacity for imposing, as a social truth, a specific way to define reality independently if it is true or false" (Pérez-Argote, 1986: p. 88). Mythical thinking is present in all 
societies; it is a myth; a "true story" instead of fable (Eliade, 1983: p. 13). It is a reality that gives meaning and determines the behavior of the people. Myths, as long as they explain reality, are part of the identity since they are a construct of what we perceive since it is part of what we interpret and the product of what we perceive; thus, it is a way to shape what we perceive from our senses for acquiring a meaning that is understood and explicative. Knowing the reality is based on our subjectivity and giving a mental representation means that we are in known realities. In this way, the mythical thinking makes the perceived phenomena understandable. They are an explanation of behaviors (despite how strange and uncommon they may sound to us) and a way to understand reality. We create a society where we were brought up based on different contexts, and due to these contexts, we may see as strange what other may consider natural. "While informal language confuses myth with fable, traditional societies see myths as a unique revelation applicable in the reality" (Eliade, 1991: p. 2). Claude Lévi-Strauss shows us an example of mythical reality in Guna people, Panama. He explains a healing chanting of Shamans that is used when there are some troubles during childbirth. Once the narration is finished and the explanation of the chanting, the author guides us throughout the process where the shaman introduces the disease in this reality so he can clear the path during the childbirth. He finished by saying "shaman mythology does not correspond to the objective reality because it lacks importance: the sick woman believes that reality and she is a member of a society that also believes in her" (Lévi-Strauss, 1992: pp. 211-227).

"In Egypt, tattooing practice has been since ancient times. Female Egyptians have tattoos on the back of their hands, on the breast, on the chin, and on the forehead; those tattoos have lasted as healing processes for four to five thousand years. A mummy of a Hathov priestess had three lines in the lower abdomen; this practice is still carried out in women to heal headaches, neuralgia, and rheumatism" (Universal Illustrated Encyclopedia, 1988: p. 878). Kayanos, in Borneo, wear tattoos to avoid and face diseases. They wear a tattoo on the wrist to prevent their soul escape from their body when the suffer from a severe disease. Moreover, their tattoos are torches that light the ones who perished during their journey to the country of the deaths (Hose, 1922: p. 322). They are also associated with the medical practice because these tattoos avoid injuries among other effects. The Burmese people protect themselves with tattoos: "Each Burmese that respect itself wears a blue tattoo from the waist, near the loincloth, to the knees. Tiger, monstrous figures are located in inscriptions in a spiral shape. The tattoos on the torso and on the arms are red because they have the aim to protect from injuries caused by any kind of weapon or to have lucky in love" (Scott, 1922: p. 437).

A healing, protector, and magic tattoo is done in the Rif, Morocco, after having visited for three days in a row the sanctuary of Sidi Abd al-Noor. There, a cow was sacrificed for the guardians and the tattooist. When the health problem lies on the skin, there is a visit to Sidi el Hach Amarani sanctuary where the sick 
person takes a shower with the water of a miraculous fountain, so they can start tattooing him dots and lines on his thigh (Cola, 1949: p. 102). Cola Alberich, who studied amulets and tattoos in Morocco, found that the swastika and the wheel in the crossare tattoo designs carried out by Berber women. The meaning of those designs is ancestral vestiges worshipping the sun. It states that the Berbers were strongly attached to the East communities, hence all those symbols. This kind of tattoos possesses magical and protective properties. "The simple cross or the Saint Andrew's cross is the most used symbol". The cross almost makes a tattooed emblem on the toes and fingers; whereas the "normal" one tattooed on the woman's breast. The heliolatric meaning representing the sun worship is indisputable: the same meaning that has possessed among the early populations ... Crosses, swastikas, and wheels (ornaments of the current tattooing practice in Morocco) indicate an ancestral worship that is still latent in the psyche despite its oblivion within the current Muslim communities. Moreover, these indicators are part of the tradition and of the symbolism that develops defensive magic properties against misfortune" (Cola, 1949: p. 109).

Line tattoos for facing rheumatism and headaches as well as tattooing practice on lumps were observed and recorded in Morocco. We asked a 60-year-old Berber woman what she was healing with tattoos and who was tattooed to record the technique, and if she practiced tattooing for healing. She answered that she indeed was healed, and she showed us her tattoos on her hands, wrists, and legs. Basically, they were two lines coming up from the knees. She told us that they were healing her joint pain.

- What about the tattoo on your hand? -It's for healing bone pain.

- You tattooed five-pointed stars on your wrists. You told us that those were for relieving you from headaches and fever. Did it work?

- What about these ones? (the tattoos on her knees) -Well, since there is some very traditional medicine to heal the pain on the feet, the doctor is very traditional and the tattoos pull out the pain.

The research carried out in Siddi Fadma (a Berber community on the mountains located $50 \mathrm{~km}$ away from Marrakesh) and what it was found was that among women, tattooing practice is done for protective properties. If they tattoo, they will be protected from the mal de ojo (evil eye) as well as they will be healed from some diseases. In the Berber community, we observed that women with lumps on their necks turn to tattoos to face their diseases. In Morocco, tattoos on Berber women are done, in most of the cases, when they are approximately 10 years old, and the mothers are in charge of tattooing them for protection. Tattoos for healing purposes are done when girls are adults. In some cases, tattoos are done by the young mother: they tattoo the chin and forehead with lines, dots, and circles. "This tattoo is called 'ayacha' (that makes live). When there is a daughter whose 'ayacha' must be incorporated, later on, to 'sayaba', the mother has to go with a specialist tattooist. This is another procedure that is carried out in puberty although there are cases that they undergo this procedure when they are married just like Berber Moroccans mainly in the Rif. Women's 
forehead, with their 'ayacha' since birth, undergo to another procedure for the 'sayaba"' (Cola, 1949: p. 91). The tattooing procedure is done with a needle, coal, and vegetable dye. A. Dembo and J. Imbelloni (s/f: 127) state that Tunisian tattoos have different names according to their purpose. Ayacha is the tattoo that preserves life. It is tattooed on the chin, the forehead, and around the eyes. It is made by a puncture and black smoke. Harcha is the tattoo for children when they come to this world with misfortune like the loss of the harvest, the death of any parent, etc.; it is one cross or two crosses, or another symbol on the forehead or on the calf. This tattoo gives immunity, manhood preservation, and protection against diseases; it is called Tesfih. It is a tattoo for an incision that begins on the knees and goes to the pubis.

In the Siddi Fata community, tattoos used as protectors talismans are shown mainly in adult women. The lines, dots, circles, and crosses are shown on the forehead, chin, hands, neck, and on the hidden areas of the body like the legs of women who suffer from joint alterations or like the tattoos we saw on the neck of women with limps. One of the most frequent interviews was that women want to remove their tattoos, and they do not wish to tattoo their daughters. However, tattooing practice is present and people go to the tattooist, always a woman, to heal and protect themselves wearing tattoos.

\section{Image 1. The woman Berber with healing tattoos}

Even though that Muslims forbid wearing tattoos, among the Berbers, they justify tattooing practices because Muhammed's daughter, Fatimah, had a tattoo on her chin. We reproduce some fragments of the interviews in Siddi-Fadma, in the Atlas Mountains. The fragments refer to tattooing practices against mal de ojo.

A woman in her fifties:

- Why did you tattoo your neck? (She has a cross on her neck) - For my protection against evil.

- What did you use to tattoo? -With needles and coal.

- Who tattooed you? -My mother did it at home (a 70-year-old woman with tattoos on the forehead, upper lip, chin, hands. She also has a lump on the neck).

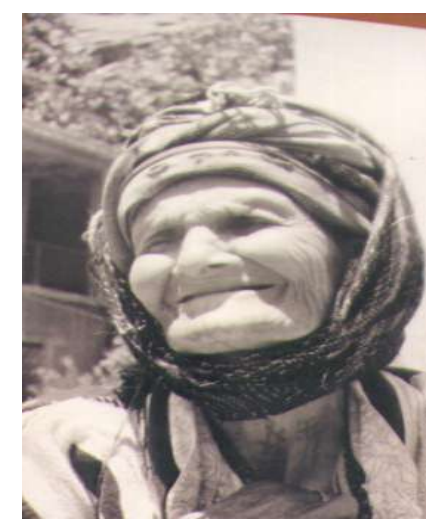

Image 1. The woman Berber with healing tattoos. 
A 30-year-old woman:

- Did your mom tattoo you? -Yes.

- And did she tattoo your sisters? -Yes.

- What about your daughters? -No.

- What did you use to tattoo? -Coal.

- Why did you tattoo? Was it because of mal de ojo? (Sharif, the translator, asked) -Yes.

- Would you like to remove it? -Yes, is there a way to remove it?

- Yes, there is. Would you like to know? -No. (She answers with a smile and then she continues doing the laundry.)

A 30-year-old woman talking to other women:

- Did your mom tattoo you? -Yes.

- Why? Evil eye?

- Did you tattoo your children? -No.

\section{TATTOOING TECHNIQUE IN THE BERBER COMMUNITY}

The tattooing technique of the community of Berber has not been recorded in any ethnologic paper until now. In order to do so, we had to get someone who wanted to tattoo us. It was difficult to find since it is a practice among women. Fortunately and thanks to a relative of Mustafá, a friend of a female tattooist in Marrakesh, agreed to make a tattoo, so we could register the technique.

1) Tattoos are made by a puncture. A sewing needle and vegetable dye are used by women. They also use it as well as powdered coal or powder of stockpot used for cooking to paint their eyes (l'antigho).

2) The vegetable dye is poured in the area of the tattoo. This vegetable dye is made of dry leaves and some blue plants. Then, powdered coal is poured over the vegetable dye. This technique is done with their hands and cotton.

3) Then, over the mix, they start shaping the tattoo. Normally, they are simple designs based on dots, lines, circles, and crosses.

4) After they shape the design with the sewing needle, the area is wiped with cotton, and then another layer of vegetable dye and powdered coal is poured in order to shape one more time the graphic of the design. However, the design can't be seen since they work in a dark area due to the vegetable dye. So, basically, the process is an estimation according to the area of the tattoo.

5) This process was carried out five times and every time that the puncture starts, the tattooist sucked the needle. In all the cases, she wiped the area with a wet cotton so the tattoo was not clearly appreciated. The tattoo, actually, started appearing three days after (the time the tattooist recommended to cover the tattooed area). During those three days, the tattooist recommended not to clean the area; we could only see some skin irritation.

6) Three days after, the blue mark appears over the irritated skin. It will dry and heal until the tattoo is already finished.

TATTOOS, FUNCTIONAL EFFICIENCY, AND MEDICAL PRACTICES IN THE WEST

Since a functional efficiency was aimed, the use of tattoos has been a resource 
of dermatologists to dye the skin with therapeutic tattoos. "It is based on the mix of different coloring substances to have the appropriate shade. In some cases, it is preferable to get a lighter shade because it can be fixable. It is advisable to compare the coloring substance with the skin tone especially with the area of the tattoo. Once it is done this stage, the process of tattooing starts with the edges while seeing if the shade of the coloring is fine. Results can't be proven after fifteen days once the swelling has passed" (Donderis, 1964: p. 43). However, this technique is not recommended with some skin troubles like Vitiligo, a disease that causes the loss of skin color in blotches gradually. There are cases in which Vitiligo affects big parts of the skin, so it will require many tattooing sessions with no certainty of getting the perfect tone with the first tattoos apart from a possibility to develop allergies. Despite the unexpected results, in 1994, Hance and his team published a technique that helped for better implants of grafts using tattoos with coloring substances because the graft implants had the inconvenient of not making the same tone of the skin (Donderis, 1964: p. 66). Tattooing efficiently has been proposed to notice a biological characteristic since tattoos are permanent. "Norman G. Lake proposes the use of small drawings or letters as a remembrance of different immunizing occultations. For instance, the letter ' $\mathrm{T}$ ' would stand for tetanus; in this case, the letter ' $\mathrm{T}$ ' would be shown on one side of the big toe; on the inner part of the lip; on the outer ear, on the mastoid; or on the hip below the iliac crest which this last one is the perfect place. Fernando D. Gómez and Juan C. Etcheverry were trying to acknowledge the individualization of the B.C.G vaccinated, so after some trials, they decided to use black Indian ink to tattoo the edge of the armpit where the vaccine was going to be shot since the skin is thin on that part of the body. Nevertheless, when a newborn was going to get its vaccine, it was difficult because the newborn kept moving. So, they decided to choose the big toe because the skin was thicker, then it was not moving a lot, and it was a discreet area but accessible to see in an examination. Therefore, they use the left big toe" (Donderis, 1964: p. 61).

Having the same intention of a functional efficiency regarding tattooing permanently as well as having to ensure the responsibilities in the surgical practice, "a bold surgeon suggested that after the intervention, the initials of the surgeon and the date of the surgery should be tattooed on the feet near the incision as a telegraphic code" (Donderis, 1964: p. 99).

With the same purpose, in 1913 an anonymous author made a proposal on Le Monde Médical. His proposal stated that in order to avoid syphilis, the member should be tattooed (foreskin, glans, etc.) with cinnabar (mercury sulfate). His reason was that tattooed people with cinnabar did not develop the disorder in the marked places of their body may be because of the mercury (Shoenfeld, 1945: p. 34).

There are medical clinics, nowadays, that practiced tattooing to cover imperfections caused by surgery. Moreover, aesthetic tattoos on the edge of the eyelid as well as on the eyebrows might be the solution for the eyeliner. People with few eyebrows or thin eyebrows turn to this resource. The same thing happens with 
people who want to delineate their mouth.

We are constantly creating a reality based on the new experiences that we are living; based on the new knowledge we are getting; based on the influence of our environment; based on the relationships we have with our body; and based on its functioning (not biologically, rather as how we are). So, based on the desired effect, we decide what is more convenient as looking for functional efficiency when someone gets a tattoo just for having an acknowledge of a biological and specific condition.

We also interview a person in Madrid. He has a lot of tattoos and he told us something curious about one tattoo on his arm ("SAN", underneath there, is an "X", and underneath a "B").

- What about this tattoo? - That is my blood type; my blood is B.

- Why did you make it? -Because if I had a car accident or whatever, people would see it.

- So, your blood type is B positive? -Indeed! (Photo: San X B.)

Image 2. Expected Effect Calculation: SAN X B

A kind of therapeutic tattoo proposed by Dr. H. Arruga was a combination of the incision technique: an injection of ink in a needle along with the application of coloring substances over the wounds. This technique was practiced in the cornea. Dr. Arruga said in his report of Eye Surgery that the aesthetic purpose of tattooing the cornea is to have a better sight and to avoid glare. "With this purpose, tattooing the cornea is used for corneal opacity or crystalline opacity in people who are blind and can't undergo a surgery. In order to improve sight and avoid glare, a tattoo that can reduce glare is used in the corneas. It is done by producing blurry lines that block the brighter areas of the cornea". The Dr. Arruga's technique and materials are the following: black Indian ink that is injected with a tuberculin needle whose plunger is greased with lanoline for accuracy, and a sharp cannula of 4 or 5 tenths of millimeter; a trephine with a slot of a third of millimeter deep in the center of the cornea; through the slot and heading to the center, the needle is introduced peripherally; once the whole of the cannula is inside the corneal tissue, the ink is injected. If the leucoma is soft, the ink spreads easily and fast throughout the area where the slot is. If the doctor can see the line, it means that the corneal cut is not deep enough, so the trephine should be done again but deeper. However, if the leucoma is hard, the doctor would barely see how the ink spreads, hence sometimes the punctures need to be done many times and in different sessions" (Arruga, 1946: p. 380). "Blascovics and Kreiker use black smoke from a candle or a glass slide prior to the surgery". "In a corneal opacity, there are a series of oblique cuts for cutting half of the thickness. Black smoke is used and is spread over the cornea for aiding the previous cuts". Regarding the palpebral cuts, Dr. Arruga mentions that "Blascvoics advice to use black smoke instead of black ink. We can get the smoke from a candle or from a glass slide prior to the surgery. The black dust remains in the glass slide so 
the doctor can spread it over the palpebral edge. It is important to mention to do this process before the two or three one-millimeter incisions deep. To spread the black smoke, it is necessary to wait for the incisions get clean from blood" (Arruga, 1946: p. 383).

\section{Image 3. Tattoo on the Cornea (Crinkle, 1946: 383)}

As the examples can show, there are different phenomena related to tattooing practice that show the reasons why the subjects decide to get a tattoo: getting a tattoo for therapeutic purposes. In the construction of realities, phenomena are developed regardless of how strange they seem to us. In western cultures, tattooing in medical practices looks for a functional efficiency where the outcome has already verified. Tattooing practice is related to a strategic calculus where there is an inaccurate probability even though the outcome does not correspond to the expected results.

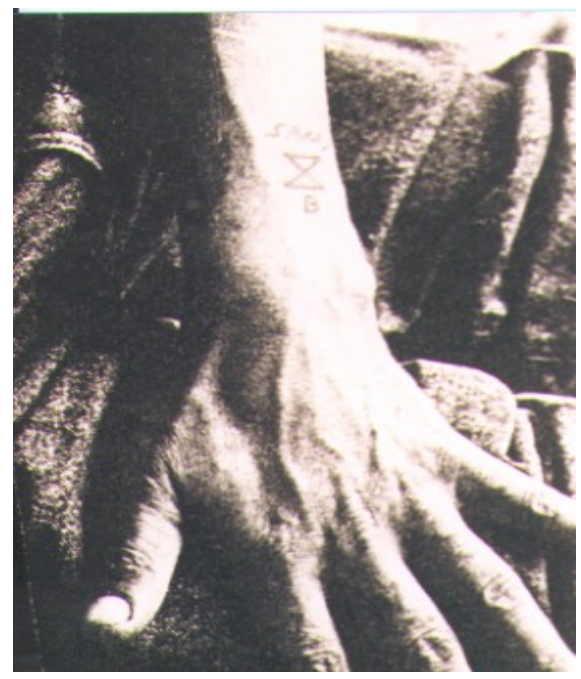

Image 2. Expected Effect Calculation(SAN X B).

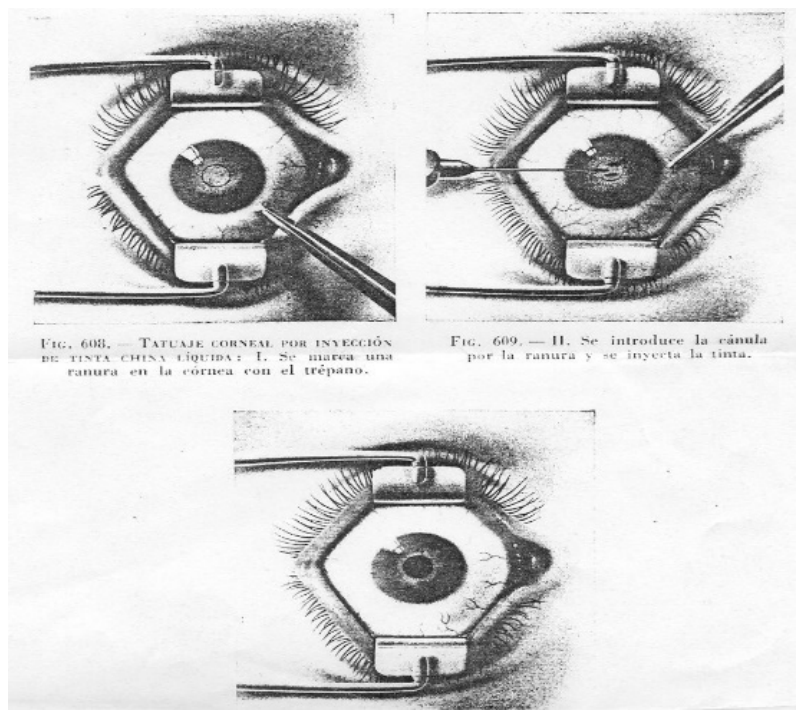

Image 3. Tattoo on the Cornea (Crinkle, 1946: 383). 


\section{Conclusion}

There are diverse phenomena that allow us to propose generative mechanisms to the practice of tattooing, these have been observed as referents from which we construct the identity, understood as a state of reality; these elements depend on the contexts in which this practice is carried out, being a necessary reference for its study, the sense that the subject gives to his tattoo, existing different senses that as reasons express the tattooed subjects: aesthetic sense; the need to keep the beloved person in mind through his tattoos; remembering significant events; as a symbol of group identity; with a playful sense; as a manifestation of belonging to certain lineages; as a protective object; as healing tattoos and those made in the past as derision, where the will of the tattooed is not present.

In Western culture, the tattoo related to homologous practices which are explained from the formation of "habitus" (Bourdieu, 1991: p. 104) that although they are not obligated, nor are they the result of a strategic calculation, without this being ruled out, they are predictable, as is the case of the tattoos that are made inside prisons, resulting in homologous practices where the diversity in homogeneity results in "homoligia" relationships (Bourdieu, 1991: p. 104), that is why the biographical facts result of the subjects who perform this type of practice, for the generative explanation of the practice of tattooing.

Mythic thinking, insofar as it explains reality in certain social groups, becomes a reference from which identity is constructed by determining behavior. Thus we can observe the practice of tattooing related to its use as protective images. In traditional communities, understood as societies in which the tattoo is part of their common sense, associated with the magical protective character, we find tattoos that are used for therapeutic purposes that are performed in areas where the illness, as is the case of tattoos performed in the Berber community on the wrists, elbows or knees, for people suffering from rheumatoid arthritis or tattoos on the neck to fight goitre.

In search of functional efficiency, in the West, the practice of tattooing has been used to make patent a condition of the patient, so that the tattoo has been a resource of dermatologists through the staining of the skin, which is not effective for patients with vitiligo since the skin will continue to de-pigment. Other applications have been proposed in search of the functional efficiency of the tattoo, hence it has been proposed to tattoo a "T" in the case of people who have been inoculated with Tetanus Toxin, proposing as appropriate places the side of the finger fat of the foot, the inner face of the lip, under the pinna of the ear, on the mastoid or on the hip just below the iliac crest, looking for a recognition to identify those vaccinated by BC G, proposing as areas to tattoo, the apex of the armpit, in the arm chosen for vaccination and the plantar aspect of the big toe that is thicker and easier to keep smooth and immobile (Donderis, 1964: p. 61). It was proposed, by a surgeon, that once the surgery was finished, the initials of the surgeon and the date of the intervention were tattooed; this was close to the incision (Donderis, 1964: p. 99). In 1946 Dr. Arruga proposed the cornea tattoo, 
with aesthetic purpose, to improve visual acuity and to avoid glare, with aesthetic purpose in cases of corneal leucoma or crystalline opacity in the blind and inoperable; to improve visual acuity and avoid glare, the tattoo is proposed by opacifying opaque areas of the cornea, which produce blurred images that obstruct the vision of other clearer areas of the cornea, which would be done with ink, which injects through half of a tuberculin-type syringe whose plunger is greased with lanolin to obtain a good fit, and a cannula of 4 or 5 tenths of a millimeter, very sharp, with a trephine is made a groove a third of a millimeter deep in the center of the cornea; through this slot and direction to the center it introduces the needle tangentially; When the entire orifice of the cannula is in corneal tissue, the Chinese ink is injected. If the walleye is soft, the ink diffuses rapidly throughout the area circumscribing the groove made; if the leucoma is hard, the Indian ink is not diffused, so the punctures have to be repeated several times and in different sessions. This can be achieved by using carbon black that is obtained by smoking a slide. The black dust that remains adhered to the slide is rubbed by the free eyelid margin, which has previously been made two or three incisions one millimeter deep over its entire length, for the application of carbon black you have to wait for the incisions they are clean of blood (Arruga, 1946: p. 383).

\section{Acknowledged Institution}

Superior Medicine School of the Instituto Politécnico Nacional, Mexico. Z.P. 11340 .

\section{Conflicts of Interest}

The authors declare no conflicts of interest regarding the publication of this paper.

\section{References}

Addon, A. C. (coord.) (1922). En Spencer, B. (Coord. ) Costumbresdel Universo, marraciónpopularde lascostumbres, ceremónias, ritosy supersticionesdetodoslospaises; variosautores; 2 tomos, Barcelona, Montañézy Simon, Editores, T.I. 1922.

Arruga, H. (1946). Cirugía Ocular. Barcelona: Salvat Editores.

Balandier, G. (1993). El desorden. La teoría del caos y las ciencias sociales. Barcelona: Gedisa.

Bourdieu, P. (1991). El sentido práctico. Madrid: Taurus Ediciones.

Cola, A. J. (1949). Amuletos y Tatuajes Marroquíes; Madrid: Consejo Superior de Investigaciones Científicas. Instituto de Estudios Africanos.

Dembo, \& Imbelloni, J. (s/f). Deformaciones intencionales del cuerpo humano de carácter étnico. Buenos Aires: Humanior, Biblioteca del Americano Moderno.

Di Tullio, B. (1966). Principios de Criminología Clínica y Psiquiatría Forense. Madrid: Ed. Aguilar.

Donderis, T. C. (1964). Estudio Médico-Legal del Tatuaje. Valencia, Tesis Doctoral.

Dumont, L. (1970). Homo Hierarchicus, ensayo sobre el sistema de castas; Madrid.

Dumont, L. (1987). Ensayos sobre el individualismoM. Madrid: Alianza Universidad. 
Eliade, M. (1983). Mito y Realidad. España: Labor.

Eliade, M. (1991). Mitos, Sueños y Misterios. Madrid: Grupo Libro 88, S.A.

Foucault, M., Vigilar y castigar; nacimiento de las priciones (1995). México: S-XXI.

García, R. S. (1994). Manual de Prisiones. México: Porrúa.

Goffman, E. (1922). Internships, Essay on the Social Situation of the Mentally Ill. Buenos Aires, Amorrortu Editors.

Hose, C. (1922). BORNEO. En Spéncer B. (Coord.); COSTUMBRES DEL UNIVERSO, narración popular de las costumbres, ceremonias, ritos y supersticiones de todos los países, T. 1 .

Lévi-Strauss, C. (1992). Antropología Estructural I, cap. X, "La eficacia simbólica". Barcelona: Paidos.

Locard (s/f). Le crime et les criminels, cit. en Donderis (1964), 67-68.

Lombroso, C. (1886). L'UOMO DELINQUENTE; "PARTE III, BIOLOGIA E PSICOLOGIA DEL DELINQUENTE-NATO”. Italia: Fratelli Bocca Editori.

Martínez, B. F. (1899) Los Tatuajesun Estudio Psicológico y Médico Legal en Delincuentes y Militares; Puebla.

Meton de Alencar Neto e José Nava (1966) Tatuagens e Desenhos Cicatriciais. Belo Horizonte. Govêrno do Estado de Minas Gerais. Brasil.

Pérez, A. A. (1986). La identidad colectiva: Una reflexión abierta desde la sociología. Revista de Occidente, No. 56.

Sabater, I. P., Jordi, J., \& Oriol Sabater, I. C. (1992). Els Tatuatges Dels Fang De L'Africa occidental; art, simbolisme i biologia en una manifestació artística poc coneguda. Adjuntament de Barcelona. Traballs del Museu Etnológic/1.

Scott, S. J. (1922). BIRMANIA. En Spéncer B. (Coord.); COSTUMBRES DEL UNIVERSO, narración popular de las costumbres, ceremonias, ritos y supersticiones de todos los países, T. 1, 1922.

Shoenfeld, W. (1945). Consecuencias Médicas del Tatuaje. Acta Médica, enero 1945, p. 34. En Donderis (1964), p. 78.

Universal Illustrated Encyclopedia (1988). Madrid: Espasa-Calpe, S. A.

Wroblewski, C. (1981). Tha Art \& Craft of Tatoo, Skin Show. Netherlands: Dragon's Dream Book. 